\title{
nombalina
}

(8)

\section{A configuração do espaço poético: concepções sobre Metricologia Latina}

Autor(es): $\quad$ Prado, João Batista Toledo

Publicado por: Associação Portuguesa de Estudos Clássicos; Imprensa da

URL

persistente: URI:http://hdl.handle.net/10316.2/31761

DOI: $\quad$ DOI:http://dx.doi.org/10.14195/978-989-721-069-3_13

Accessed : $\quad$ 26-Apr-2023 06:59:22

A navegação consulta e descarregamento dos títulos inseridos nas Bibliotecas Digitais UC Digitalis, UC Pombalina e UC Impactum, pressupõem a aceitação plena e sem reservas dos Termos e Condições de Uso destas Bibliotecas Digitais, disponíveis em https://digitalis.uc.pt/pt-pt/termos.

Conforme exposto nos referidos Termos e Condições de Uso, o descarregamento de títulos de acesso restrito requer uma licença válida de autorização devendo o utilizador aceder ao(s) documento(s) a partir de um endereço de IP da instituição detentora da supramencionada licença.

Ao utilizador é apenas permitido o descarregamento para uso pessoal, pelo que o emprego do(s) título(s) descarregado(s) para outro fim, designadamente comercial, carece de autorização do respetivo autor ou editor da obra.

Na medida em que todas as obras da UC Digitalis se encontram protegidas pelo Código do Direito de Autor e Direitos Conexos e demais legislação aplicável, toda a cópia, parcial ou total, deste documento, nos casos em que é legalmente admitida, deverá conter ou fazer-se acompanhar por este aviso.

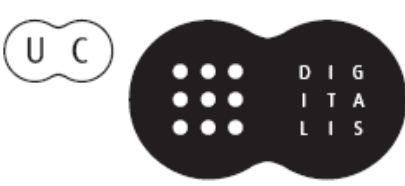




\section{Espaços e Paisagens}

\section{Antiguidade Clássica e Heranças Contemporâneas}

Vol. I Línguas e Literaturas. Grécia e Roma

Francisco de Oliveira, Cláudia Teixeira, Paula Barata Dias (coords.)

IMPRENSA DA UNIVERSIDADE DE COIMBRA 


\title{
A CONFIGURAČ̃̃ DO ESPAÇO POÉTICO: CONCEPÇÔES SOBRE METRICOLOGIA LATINA ${ }^{1}$
}

\author{
João Batista Toledo Prado² \\ Universidade Estadual Paulista
}

\begin{abstract}
If the poetic effects, that are produced as a within the plan of contents of a poem, can create a certain climate or suggest a certain atmosphere, then it would be also correct to say, by extending and taking advantage on a topologic metaphor, that the plan of expression constitutes the very place from where poetic effects arise. Thus, the plan of expression constitutes some kind of natural landscape for a poem. When we deal with the poetry from the Greco-Latin antiquity, the poetic space has a quite well-delimited measuring tool, which is to say Metrics. This article discusses some key-concepts by means of which certain ancient metricologists have considered the nature, functionality and classification of some fundamental meters belonging to the old Latin poetry.
\end{abstract}

Keywords: Latin literature, metricology, poetics of expression.

Palavras-chave: literatura latina, metricologia, poética da expressão.

A base sobre a qual se assenta teoricamente essa investigação é, a princípio, a aplicação de certos conceitos lingüísticos para a compreensão de fenômenos métricos, como aquele que analisa efeitos acústicos pela compreensão de seu valor opositivo e contrastivo, o que geralmente se faz em estudos fonológicos aplicados ao tema. Esse é o caso, por exemplo, de Perini (1982: 206) ao afirmar ser um valor psicológico a natureza da oposição entre breves e longas.

Os estudos e trabalhos realizados até o momento sobre métrica clássica latina podem ser sintetizados grosso modo em dois grandes grupos de textos: 1) as fontes antigas, ou seja, os textos supérstites da tradição manuscrita, escritos em latim e, às vezes, também em grego, por autores que ainda falavam tais línguas antigas; e 2) as obras modernas, que implicam estudos e compilações feitos em épocas mais recentes, em geral redigidos em línguas modernas, embora até pelo menos o século XIX algumas delas o tenham sido também

\footnotetext{
${ }^{1}$ Expressamos, aqui, agradecimento ao Conselho Nacional de Pesquisa e Desenvolvimento Científico $(\mathrm{CNPq})$, que tornou possível realizar um estágio de pesquisa Pós-Doutoral no Exterior (bolsa PDE), em Roma-Itália, de fevereiro do corrente a janeiro de 2009. Este texto constitui, já, alguns dos primeiros resultados (ainda que incipientes) da pesquisa que se está desenvolvendo.

${ }^{2}$ Professor de Língua e Literatura Latinas da Faculdade de Ciências e Letras da Universidade Estadual Paulista (UNESP), SP - Brasil.
} 
em latim (como os textos reunidos por Heinrich Keil, na obra Grammatici Latini).

Esses dois grandes grupos ainda comportam subdivisão:

1.a. textos de autores latinos voltados a temas outros que não a métrica, mas que contêm valiosas informações sobre ela e sobre questões de poética (nesse grupo entram, entre outras, certas obras de retórica, como, por exemplo, o Orator e o De Oratore, de Cícero, e a Institutio Oratoria, de Quintiliano);

1.b. textos de gramáticos latinos que contemplam exposições sobre a métrica em seus manuais técnicos (no âmbito da pesquisa em curso, esse subgrupo compreende textos de gramáticos compilados por Heinrich Keil no volume 6 da sua obra Grammatici Latini, intitulado Scriptores artis metricae, e que reúne os textos "esticológicos" desses autores antigos);

2.a. os manuais de métrica clássica grega e latina (e.g.: o de Crusius, de Gubernatis, de Hardie, de Lavarenne, etc.), que se ocupam de descrever o enorme número de possibilidades de realização dos diversos pés métricos nos muitos tipos de versos empregados pelos poetas clássicos;

2.b. os estudos críticos, que compreendem livros, ensaios e artigos voltados à discussão de particularidades de emprego e ocorrência de pés métricos diversos nos poemas da antiguidade, tais como o tipo de escolha lexical feita por determinado autor para construir certos pés métricos dos versos por ele utilizados, sua freqüência de ocorrência, formas de escansão, etc.

Em contraste com o ponto de vista metodológico adotado na presente investigação, constatam-se certos problemas de concepção e de abordagem da matéria, verificados nos subgrupos há pouco apontados, como segue:

No subgrupo 1.a., ainda que haja preciosas lições a serem coligidas nas obras indiretas (porque destinadas a discussões que não abordam nem a Poética nem a métrica diretamente), por um lado elas se encontram dispersas em meio à matéria de discussão não especializada, por outro, mesmo em relação àquelas que já foram identificadas em estudos modernos, sempre é possível fazer novas interpretações a partir delas, em particular à luz do progresso que as discussões mais recentes do assunto propiciam, mesmo por meio de trabalhos de cunho estatístico;

No subgrupo 1.b., embora destinados à matéria da métrica latina e, portanto, sejam textos especializados, o que predomina nos antigos manuais de métrica clássica é uma extremada - ainda que conscienciosa - atividade descritiva de grande empenho taxionômico, que, na maior parte das vezes, não conduz a considerações de cunho propriamente teórico. É possível, no entanto, deduzir, dos diversos sistemas e subsistemas da taxionomia métrica, certos procedimentos analíticos que implicam teorias que lhes são subjacentes;

No subgrupo 2.a., a despeito da inegável utilidade do esforço descritivo empreendido pelos estudos de métrica constantes dos manuais mais 
modernos, que, apoiados na descrição e taxionomia dos seus predecessores gregos e sobretudo latinos, emprenharam-se em catalogar um sem-número de ocorrências de metros em diversas possibilidades combinatórias, não se constata ali uma verdadeira preocupação em revelar a coerência e conseqüência dos dados catalogados em relação à natureza do objeto que os originou, ou seja, a poesia. Essa postura gerou, invariavelmente, um incomensurável conjunto de normas que passaram a funcionar como instrumento de análise dos poemas. As análises permitidas pelas descrições e prescrições desses manuais são, em geral, de natureza atomizante, e os resultados que daí advieram dificilmente poderiam ser reunidos numa síntese salutar, que fizesse retornar o estudioso a seu objeto - a poesia do poema - com um novo entendimento e, por isso, acabam formando um conjunto que costuma deixar a desejar, quanto à relação mantida com a identidade do fenômeno observado;

No subgrupo 2.b., observa-se que, não obstante haver novas e instigantes propostas de trabalho (como as pesquisas de Dangel, Tola, Ceccarelli, DeNonno, Luque Moreno, etc.), a métrica dos tratados, indiciados aqui no subgrupo 2.a., tem formado a base de que se apropriou quase sem questionamento a maior parte dos pesquisadores contemporâneos, a quem tem mais interessado a multiplicação dos detalhes depreendidos da investigação das obras de autores clássicos, por meio de levantamentos freqüentativos de ocorrências, por exemplo; também seu modo de encarar o problema dos fundamentos por que se pauta a métrica irá permear os estudos mais recentes da versificação antiga: em geral, os modernos autores de artigos sobre o assunto, baseando-se nos postulados da métrica tradicional, têm antes feito chegar os ecos dessa tradição até o presente do que procurado princípios gerais, que possam regular o emprego da grande multiplicidade das matrizes prosódicas, geradoras dos variados versos da poesia antiga.

O modelo teórico que parece produzir um resultado capaz de superar as limitações e óbices há pouco descritos é, principalmente, o proposto por Perini (1982), cujo tratamento da matéria revelou ser, até agora, o mais inovador e capaz de deduzir princípios norteadores da variabilidade métrica.

Para esse autor, a explicação dos fenômenos métricos reside no entendimento de que os múltiplos efeitos, gerados no plano de expressão metricamente regulado, devem ser abordados como resultado de uma operação psíquica - equiparável à noção saussureana de valor (Saussure 1973: 139-40) - que pouco ou nada tem de físico nem de material, muito menos resulta da natureza do som.

Tal concepção implica, de maneira imediata, a necessidade de tratar dados da sonoridade que constituam a realização métrica do verso não em seu aspecto material, mas nos jogos de contrastes encetados pelo poeta, isto é, é desejável investigar o plano prosódico levando-se em conta não a natureza do som, mas, sim, suas diferenças opositivas, as quais se situam no nível da própria língua latina, enquanto sistema formal. Tornam-se, então, imprescindíveis algumas noções de fonética e de fonologia, a fim de tornar 
operacional o valor contrastivo dos sons no interior de um poema, e a esse propósito, fazemos nossas as palavras de Lima, ao pronunciar-se sobre o hexâmetro de Virgílio:

"Mesmo sem proceder a uma investigação mais acurada no campo da terminologia aplicada àqueles fatos que envolvem algum dos 5 sentidos na poesia, já a própria descrição fonética e fonológica, ao incorporar e consagrar designaçôes que só são plenamente compreensíveis quando associadas a idéias básicas, inconfundíveis como explosão, oclusão ou expressas por adjetivos derivados, que tiram, por isso, motivação referencial do conceito que os deriva, como velar, dental, palatal, etc., fornece o fundamento para a apreciação estética de artefatos da semiótica quais sejam hexâmetros virgilianos. [...] Assim, a leitura metalingüistica da poesia, sem fugir à natureza verbal do seu objeto, se fará, de início e em boa parte, com os mesmos termos utilizados na descrição da linguagem verbal no plano da fonética e da fonologia, agora voltados mais à caracterização de fenômenos sonoros do que à mera classificação inconseqüente deles. ${ }^{\text {”3 }}$

Para o tratamento do estrato da matéria verbal do verso, Perini reclama o mesmo princípio geral que norteia os atos de fala ordinários, pelo menos no que respeita à indiferenciação - concreta, isto é, física - dos componentes lexicais num ato de fala oral:

\begin{abstract}
"No interior do verso considerado como frase - segmento rítmico da cadeia silábica, que é um todo unitário em si mesmo - não existem intervalos, e muito menos pausas, entre uma palavra e outra: conticuereomnesintentiqueoratenebant ${ }^{4}$. Nesse encadeamento de sílabas, a separação de palavras - isto é, a individualização de valores semânticos particulares, tal como se reflete no uso gráfico corrente - é um fenômeno de ordem psicológica, não fonética; por isso, não são levadas em conta as eventuais pausas expressivas, que são um fato estilístico e não incidem minimamente sobre a continuidade do segmento."
\end{abstract}

Mesmo para a materialidade do som vocálico, o autor destaca o caráter psíquico da linguagem, creditando-lhe a importância interpretativa na segmentação conceitual de um contínuo sonoro, que não se caracteriza por demarcar os significantes a que eles estão associados. Conclui-se que, para Perini, vale aquele princípio segundo o qual "Em matéria de linguagem, há somente uma lei universal: a do valor expressivo dos signos."

${ }^{3}$ Lima, 1995b: 1.

${ }^{4}$ Olhando atentos, calaram-se todos (Verg. A. 2.1. Trad. nossa).

5 "All'interno del verso considerato come frase - ritmico segmento di catena sillabica, del tutto unitario in sé stesso - non esistono intervalli, e tanto meno pause, tra parola e parola: conticuereomnesintentiqueoratenebant. In questa collana di sillabe la separazione delle parole cioè l'individuazione dei singoli valori semantici, quale si riflette nel corrente uso gráfico - è un fenomeno d'ordine psicologico, non fonetico; perciò non va tenuto conto delle eventuali pause espressive, che sono un fatto stilistico e non incidono minimamente sulla continuità del segmento." (Perini 1982: 205-6. Trad. nossa).

6 "En matière de language il n'y a qu'une loi universelle, celle de la valeur expressive des signes." (Rosset 1970: 135. Trad. nossa). 
Para aplicar tais princípios teóricos, porém, está-se pensando, aqui, no fator de expressividade da poesia clássica latina, em função do qual provavelmente ocorrem certas permutas entre tipos de pés métricos. Convém lembrar que a poesia latina é de base quantitativa, i. e., nela, os padrões fonológicos da língua estão a serviço da produção de um ritmo verbal, criado por uma oposição de base, pautada na diferença entre o traço fonológico de vogal breve versus o traço de longa.

Para a consecução do ritmo verbal do verso, por exemplo num hexâmetro datílico (um verso de seis pés métricos, compostos, ao menos idealmente, por seis dátilos, ou seja, por seqüências trissilábicas, em que a primeira sílaba é longa e as duas outras que se lhe seguem são breves), um dátilo poderá ser substituído, em certas posições, por um espondeu (pé dissilábico, com ambas as sílabas longas).

O critério para uma permuta dessa natureza é perfeitamente lógico, uma vez que se atribui um tempo (em latim, mora = demora ou duração, cf. Lima, 1995: 62; ou tempo primo = tempo primeiro, cf. Perini, 1982: 211) a cada sílaba breve, ao passo que cada longa vale, por oposição, dois. Mesmo aqui, seria prudente observar que os tempos em questão não são grandezas físicas, mas, sim, psicológicas, i. e., não está em causa a duratividade material da prolação do som vocálico, mas, sim, seu valor intrínseco, percebido pela consciência do falante natural do idioma latino, que, ao ouvir, sente, na oposição entre as duas grandezas de base (breve X longa), diferenças específicas, e as convalida na apreensão de um verso como unidade do poema.

Há, porém, outras espécies de permuta cuja natureza tende a resistir a uma explicação mais racional como a da equivalência temporal psicológica, que permite a substituição de um dátilo por um espondeu. Nessas outras espécies, é possível substituir um pé métrico, que equivale a um valor temporal, ou seja, cronológico, por outro com valor diferente, como acontece, por exemplo, com os versos iâmbicos.

Assim, por exemplo no senário iâmbico,i.e.,num verso composto idealmente por seis iambos (pé dissílabo, cuja primeira sílaba é breve e a segunda é longa), é possível permutar o iambo por um tríbraco (pé trissílabo, formado por três breves), o que ainda respeita o critério ou razão lógica de equivalência temporal entre pés métricos, já que ambos equivalem a três tempos. $\mathrm{O}$ que sucede, entretanto, é que, no mesmo tipo de verso, é possível permutar um iambo por um espondeu, por um dátilo, por um anapesto (verso trissílabo, formado de duas breves e uma longa) ou por um proceleusmático (verso quadrissílabo, formado de quatro breves), todos com valor de quatro tempos.

Os manuais de métrica são praticamente unânimes em afirmar que o senário iâmbico raramente é puro, ou seja, quase nunca é formado apenas por iambos

\footnotetext{
${ }^{7}$ A figura prosódica ideal de um hexâmetro (bem como a de qualquer verso clássico) não leva em conta, naturalmente, o momento de retorno da sílaba final, que atua como pontuação do verso e que é fonologicamente neutralizada (cf. Prado 1997: 171-2), de tal forma que, como se sabe, o último pé de um hexâmetro será sempre ou um dissílabo espondaico (quatro tempos) ou trocaico (três tempos).
} 
(daí chamarem-no senário iâmbico livre), o que faz do sistema aparentemente livre de permuta algo, de fato, corriqueiro, ainda mais quando se constatam tais substituições na prática da escansão, seja, por exemplo, em poemas de Catulo, seja nas comédias de Plauto e Terêncio, seja nas fábulas de Fedro, e assim por diante. Ademais, tal problema é agravado pelo fato de os poemas de base trocaica admitirem o mesmo sistema de substituições não cronológicas.

Para enfrentar essa questão, uma hipótese de trabalho pode ser a de que, talvez, na antiga poesia latina, atuavam dois sistemas de valor prosódico no verso: um, lógico, baseado na equivalência das seqüências de pés de mesmo valor cronológico; outro, sublógico, cuja funcionalidade atesta um sistema de equivalência de natureza talvez tipológica, isto é, que atuaria com respeito a pés métricos considerados equivalentes por pertencerem a determinado tipo de matriz fonológica.

A fim de explicar essa dupla natureza do sistema de correspondências métricas da poesia latina, poder-se-ia lidar, a princípio, tanto com a hipótese da produção de efeitos de sentido muito específicos e atualizados em situações determinadas (a da representação teatral ou a da leitura pública de poemas, por exemplo), que poderiam levar, talvez, à produção de um efeito de casualidade e/ou de coloquialidade, adequados à comunicação de certos conteúdos, como com o postulado da derivação métrica, proposta desde, pelo menos, Césio Basso $^{8}$ e retomada pelos esticólogos posteriores, como Mário Vitorino ${ }^{9}$ e Terenciano Mauro ${ }^{10}$.

Até o momento, aparentemente nunca se atentou para a possibilidade de que, entre os antigos latinos, a concepção, segundo a qual uma figura prosódica - um pé métrico - possa ter-se diferenciado por mecanismo de derivação a partir de outra(s), que atuaria $(\mathrm{m})$ como matriz(es) fonológica(s), fosse capaz de explicar os dispositivos de permuta não baseados em equivalência temporal.

Seria oportuno, por isso, organizar um conjunto de juízos antigos sobre o tema, racional e metodicamente selecionados pelo viés de suas mútuas correspondências, bem como pelas deduções que permitissem reduzi-los a formulações únicas e coerentes, de modo a que ele permita várias formas de análise dos dados ali contidos, como, por exemplo, as diversas concepções

\footnotetext{
${ }^{8}$ Basso, pelo que se sabe, o primeiro a falar disso em Roma, sustenta a teoria da derivação métrica em vários momentos, como se pode ler no Caesii Bassi fragmentum de metris coligido por Keil (Obs.: todas as edições de textos de gramáticos antigos aqui citados baseiam-se na edição de Keil, H. Itália; cf.). Embora Basso tenha vivido no séc. I d.C., a idéia de derivação, transposta para os domínios das artes plásticas e da retórica, estava já presente pelo menos desde Platão (cf. Timeu, 50a), que a denomina metapláttein, como lembra Dangel 2001. Tal fato permite supor que o conceito estivesse na base de toda a produção poética latina.

${ }^{9}$ E cuius genere hae metrorum species gignuntur, diphilium seu choerilium, lagaoedicum seu archebulium, aeolicum sive sapphicum et cetera, de quorum statu ac ratione suo loco dicemus. (De cujo tipo [= das formas de divisões de um hexâmetro datílico] nascem estas espécies de metros: o difílio ou o querílio; o logaédico ou o arquebuleu; o eólico ou o sáfico, etc., sobre cujo estatuto e proporção falaremos em momento adequado). (Marius Victorinus, "De dactylico metro". Liber 2, in: Marii Victorini Artis Grammaticae Libri III, v. Keil, 1961).

${ }^{10}$ Esse é, aliás, o princípio norteador de toda a exposição dos metros do manual de Terenciano Mauro, intitulado De litteris, de syllabis, de metris; v. Keil, 1961.
} 
taxionômicas e conceituais sustentadas pela doutrina métrica de cada diferente autor que integrasse um tal córpus ${ }^{11}$.

\section{Bibliografia}

J.Brodsky (1994), Menos que um.Trad. Sérgio Flaksman. São Paulo: Companhia das Letras.

J. Dangel (org.). (2001), Le poète architecte. Arts métriques et art poétique latins. Louvain/Paris/Sterling (Virginia): Peeters.

H. Keil (Keilii, H). (1961), "Scriptores Artis Metricae" (v. 6), in Grammatici Latini ex recensione Henrici Keilii. Leipzig (=Hildesheim): Georg Olms, $1874.8 \mathrm{v}$.

A.D. Lima (1995a), Uma estranha lingua?: questões de linguagem e de método. São Paulo: EdUNESP.

. (1995b), "Superação de restrições métricas do hexâmetro latino". Araraquara: artigo inédito.

G. B. Perini ("31982), "Fondamenti di métrica". in A. Traina, G. B. Perini, Propedeutica al latino universitario. Bolonha: Pàtron, 201-41.

J. B. T. Prado (1997), Canto e encanto: o charme da poesia latina. Contribuição para uma Poética da Expressividade em língua latina. São Paulo: FFLCHUSP-SP (Tese de doutorado policopiada).

C. Rosset (1970), L'Enseignement élémentaire du Latin. Paris: Université-Paris IV (Tese Mimeogr.).

F. Saussure ( $\left.{ }^{4} 1973\right)$, Curso de lingüistica geral. Trad. A. Chelini, J. Paulo Paes e I. Blikstein. São Paulo: Cultrix.

F. D. Teixeira (2005), Os Fragmenta de Césio Basso: leitura crítica e tradução anotada. Araraquara: FCL-UNESP-CAr (dissertação de mestrado policopiada - Programa de Pós-Graduação em Estudos Literários).

Virgile (181910), P. Virgili Maronis Opera. Texte par E. Benoist, revue par M. Duvau. Paris: Hachette.

${ }^{11}$ A respeito da grafia aqui adotada para a palavra latina corpus, q.v. o texto "PARA NÃo perder o latim. Análise total, por João Batista Toledo Prado em 11/5/2004”, disponível no site do Observatório da Imprensa, url: http://observatorio.ultimosegundo.ig.com.br/artigos. asp?cod=276JDB005 (acesso em 25/03/2008). 